\title{
Exploration of Middle School Students' Ideas of Fine Dust Issues Using Issue Concept Maps
}

\author{
Gahyoung Kim \\ Ewha Womans University \\ 52, Ewhayeodae-gil, Seodaemun-gu, Seoul o376o, Korea \\ gahyoung.kimı@gmail.com \\ Kongju Mun \\ Seoul National University \\ 1 Gwanak-ro, Gwanak-gu, Seoul o8826, Korea \\ mkj5486@snu.ac.kr \\ Hyunju Lee \\ Corresponding author, \\ Ewha Womans University \\ 52, Ewhayeodae-gil, Seodaemun-gu, Seoul o376o, Korea \\ hlee25@ewha.ac.kr
}

Received: 1 August 2020 | Revised: 19 November 2020 |

Accepted: 2 November 2020

\begin{abstract}
This study introduces issue concept maps (IC map) as an instructional tool for exploring students' idea about socio-scientific issues (ssI). By visualizing students' ideas in two dimensions, context and occurrence, IC maps represent what kinds of ideas students have on the issues, and how their ideas change and connect. In the study, we implemented a ssi program on fine dust for 77 seventh graders and used IC maps to investigate how their ideas changed after the program. Students collaboratively constructed IC maps in groups before and after the program. Results show that the number of ideas written on IC maps significantly increased after the program from 92 to 254 ideas, indicating that the program contributed to enhancing students' awareness about the issues in terms of its causes, effects, and countermeasures at various context
\end{abstract}


levels. Students also presented a greater variety of types of connections among their ideas after the program.

\section{Keywords}

fine dust - issue concept map - socioscientific issues - changes of student ideas

\section{Introduction}

In recent years, people throughout the world have suffered from respiratory diseases due to the severity of fine dust. Some industries have suffered economic losses (Kim et al., 2015). Fine dust is a type of spherical particulate matter (PM) floating in the air and is often classified by its diameter using codes such as PM1O and PM2.5. Most dust is usually filtered by the nose's and bronchi's mucous membranes during breathing, but the respiratory system has difficulty filtering fine dust, so much of it reaches the lungs. Ultra-fine dust in particular absorbs carcinogens from the atmosphere, enters the body, and penetrates the lungs and can cause inflammation and cancer (Chithra \& Madanayak, 2018; Deng et al., 2016; Park, 2014). The number of fine dust alerts and warnings in early 2018 increased $68.8 \%$ compared to 2017 (Lee, 2018). Because the issue of fine dust has mostly been caused by overdevelopment, there is a need to educate students about its seriousness and participate in efforts to reduce it. For this reason, the issue of fine dust has become a subject that frequently appears in science lessons (Kim, 2018).

Previous studies (Choi, 2018; Park, 2014) have shown that students' understanding of the fine dust issue in terms of its causes, phenomena, and effects on individuals and society seems to be limited. For instance, Choi (2018) surveyed 206 college students over the age of 19 using a questionnaire to investigate their perceptions, knowledge, and attitudes on fine dust. The results showed that their knowledge and attitudes related to fine dust was relatively low even though they were aware of the seriousness of fine dust-related issues. Park (2014) also examined middle school students' and teachers' understanding of fine dust issues and reported the shallowness of their knowledge on the issue. Therefore, many researchers have tried to improve students' conceptual understanding of the issues, with the assumption that how deeply they understand the issue affects their practical actions to solve the issues (An et al., 2020; Dijkstra \& Goedhart, 2012; Herman, 2018; Kim \& Lee, 2017). An et al. (2020), for example, implemented a fine dust issue program for elementary school 
students and found that students' interest in the issue significantly increased and their willingness to take action for reducing the occurrence of fine dust was promoted. Kim and Lee (2017) also observed students' willingness to act to resolve fine dust issues after participating in a socio-scientific issues (SSI) program.

These findings have led many researchers and educators to try to investigate students' understanding of and ideas about the issues using various types of instruments; however, in many studies, multiple-choice, true or false, or Likert-type instruments have been used. Although such instruments efficiently measure students' understanding of these issues, they are limited when educators aim to explore how deeply students understand issues and how they examine them from different angles (Anderson \& Wallin, 2000; Boon, 2010; Boyes \& Stanisstreet, 1997). In particular, understanding ssis is quite different from understanding scientific knowledge in ordinary science classes (Kim et al., 202O). In ssi classes, students not only learn scientific knowledge related to sSI, but explore the causes of, effects of, and countermeasures to deal with ssis in individual, social, and global contexts. In addition, because ssis by their nature involve diverse values and perspectives, it is necessary to examine the issues from various perspectives (Kahn \& Zeidler, 2016). Considering these characteristics of ssis, it is necessary to develop and use instruments that can reflect the inherent natures of ssis when exploring students' understanding of them.

For these reasons, Mun et al. (2014) introduced an issue concept (IC) map as a tool to explore students' understanding of ssis. They developed IC maps on the basis of ideas about concept mapping (Novak, 1990). Brody et al. (1989) noted that using concept maps is more effective to investigate students' understanding of and reasoning about ill-structured problems like ssis. The IC map that Mun et al. (2014) developed is organized in two dimensions: one is context (personal, societal, and global) and the other is occurrences (causes, effects, and countermeasures). Such a structure, composed of nine cells, is suitable for examining students' understanding of ssi from various angles. Using the IC map, Mun et al. (2014) explored high school students' ideas of climate change. They allowed students to individually express their ideas on IC map in terms of causes of, phenomena of, and countermeasures to deal with climate change at the personal, societal, and global levels. The results indicate that IC map contributed to the researchers' ability to identify patterns of students' ideas and misconceptions about climate change.

Therefore, in this study, we implemented an ssi program on the fine dust issue and investigated students' understanding using IC maps. In the ssI program, we encouraged the students to collaboratively communicate with their 
peers while constructing IC maps to enhance their understanding (Tekbiyik, 2015). We assumed that IC maps that the students constructed could represent the changes in their ideas on the issues. The guiding research questions can be summarized as follows. First, what were the changes in the students' ideas on the fine dust issues represented on IC maps after the ssi program? Second, how did the students make connections among ideas about the fine dust issues on IC maps?

\section{$2 \quad$ Methodology}

\subsection{Participants}

The participants were 77 seventh graders in two middle schools located in Seoul Metropolitan City who voluntarily participated in the ssi program on fine dust issues. The ssi program was implemented as a part of a free-semester curriculum. The researchers obtained consent from the students and their parents to participate in this study.

\subsection{Context of the Study}

The ssi program on fine dust issues lasted 16 class periods over 8 weeks during the free semester. To expand the scope of students' understanding on the issue, we included not only in-school classes but also outside-of-school classes in the program, which utilized various resources within the local community (e.g., the Meteorological Administration, local administration offices, and community health centers; Kim \& Lee, 2017). The program was designed based on the concept of sense of place (Jorgensen \& Stedman, 2001; Power, 2004; Semken \& Freeman, 2008; Semken, Freeman, \& Watts, 2009). Power (2004) claimed that direct experiences of learning in meaningful places, like students' own communities where they feel they belong, often become a driving force for them to actively engage in the issues and to take action.

The ssi program conducted in the present study consisted of the following four stages. First, in the recognition stage, the students recognized the problematics of fine dust. They searched the AirKorea website to be aware of the current regional air quality and fine dust concentrations. They also visited the local meteorological center to meet experts in order to get further information on fine dust. Second, in the exploration stage, the students investigated and compared various types of masks through activated carbon filtration experiments. They also visited the local administration office and community health centers to study diseases caused by fine dust. Third, in the sharing stage, the students shared their knowledge and learning experiences with community 
residents. For example, they explained how to properly wash one's hands using uv lights and surveyed the elderly's awareness of the problematics of fine dust. Lastly, in the action-taking stage, the students came up with feasible ideas for preventing potential harm from fine dust and constructed posters or brochures to advertise the ideas to their peers. Some of the students posted them in their classrooms, nearby apartment complexes, and community health centers for the elderly.

\subsection{Issue Concept Map}

The IC map is an instructional tool to identify students' ideas about ssis (Mun et al., 2014). Unlike normal concept maps, as suggested by Novak and Gowin (1984), the IC map has the advantage of allowing exploration of students' ideas and thoughts on issues in various dimensions. It guides students to consider the causes of, effects of, and countermeasures to deal with ssis from personal contexts to societal contexts and global contexts (see Table 1). As can be seen in Figure 1, the IC map has 9 cells $(3 \times 3)$ based on contexts (personal, societal, and global) and occurrences (causes, effects, and countermeasures). Students are encouraged to write down some ideas in each cell and to make connections among the ideas by drawing lines between ideas. If the connections between the ideas indicate causal relationships, they are marked by arrows. If one idea subsumes or is equivalent to the other, the relations are represented by straight lines. In the previous study (Mun et al., 2014), an IC map was implemented in high school students. However, even middle school students were able to use the IC map because it clearly guided them on what to write about the issues.

TABLE 1 Definition of occurrences and contexts in IC-maps

\section{Definition}

\begin{tabular}{|c|c|c|}
\hline \multirow[t]{3}{*}{ Occurrences } & Cause & What are the causes of the issue? \\
\hline & Effect & $\begin{array}{l}\text { What are the possible impacts and consequences } \\
\text { of the issue? }\end{array}$ \\
\hline & Countermeasure & $\begin{array}{l}\text { What are some countermeasures to solve the } \\
\text { issue? }\end{array}$ \\
\hline \multirow[t]{3}{*}{ Contexts } & Personal level & $\begin{array}{l}\text { In the context of individuals or family (e.g., I, My } \\
\text { family) }\end{array}$ \\
\hline & Societal level & $\begin{array}{l}\text { In the context of the local community or nation } \\
\text { (e.g., My school, My community, My country) }\end{array}$ \\
\hline & Global level & $\begin{array}{l}\text { In the context of between several nations or } \\
\text { global context (e.g., Asia, Europe, Global) }\end{array}$ \\
\hline
\end{tabular}




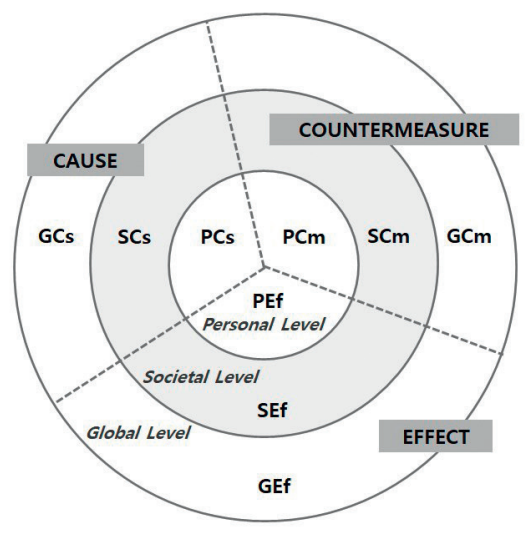

A

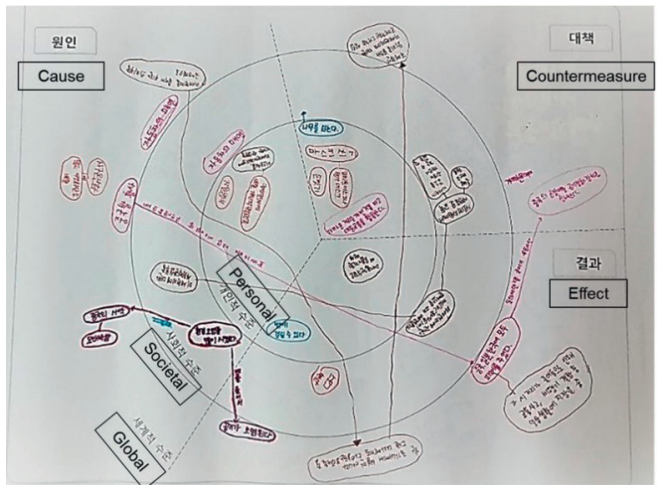

B

FIGURE 1 IC map and an example of student group IC map

\subsection{Data Collection and Analysis}

Since the purpose of the study is to present how well IC maps represent students' ideas about fine dust issues and how their ideas change after the ssI program, we collected IC maps that 14 groups of students constructed before and after the program. In order to distinguish and compare their ideas of fine dust issues, we asked students to use different colored pencils when drawing the IC maps after the program so we could distinguish their comments from those made on maps before the program. Using the different colored pencils, on the post-program IC maps, students added or deleted some ideas, moved one cell to another, and drew arrows and straight lines. We provided the students a clear explanation on how to collaboratively construct IC maps with their peers before they drew. On average, it took about 30 minutes for them to construct an IC map.

To analyze the IC maps, we started to organize the ideas that the students had written in each cell of the IC maps into Excel. The total number of ideas written by the students was 92 in pre-program IC maps, and 254 ideas were newly added in post-program IC maps (346 ideas in total). First, as shown in Table 2, we re-organized the ideas using two dimensions, context levels and occurrences, and tried to identify commonalities and differences among the ideas of the issues as coding the ideas. When coding the ideas, we assigned the same codes to the ideas if their meanings were similar. For instance, for "when I cook the mackerel at home," "grilled mackerel," and "grilled pork belly" we used the code "cooking." This resulted in the creation of 57 codes from the data. We also investigated whether the students had any misunderstanding of the issues. Second, we carefully compared pre-program IC maps with post-program 
IC maps to identify the changes in the ideas. In other words, we examined which ideas were added or deleted, which ideas had been moved to other cells, and how they made connections between the ideas using arrows and straight lines. To guide readers to better understand the analysis of IC maps, we provide examples of students' IC maps in Figures 2 and 3. Last, examined the changes in order to identify patterns. To increase the credibility of our analysis, each researcher independently went through the analyzing process and continued to discuss until a consensus was reached (Lincoln \& Guba, 1985).

\section{$3 \quad$ Results}

\subsection{Changes in Student' Ideas about Fine Dust}

The number of ideas written on IC maps significantly increased, from 92 to 254 ideas, in all nine cells after the program on fine dust, indicating that the program contributed to enhancing students' awareness on the issues in terms of its causes, effects, and countermeasures at various context levels. As shown in Table 2, in the pre-program IC maps, the ideas were more concentrated on the causes of and countermeasures to deal with fine dust. In the pre-program IC maps, the students also tended to consider the causes, effects, and countermeasures mainly in the personal context (about $50 \%$ ). However, in the postprogram IC maps, the number of ideas in the effects cell showed a considerable increase. In addition, the scope of students' ideas greatly expanded, from the personal context to the societal and even global contexts.

The results of a close examination of the students' ideas in two dimensions are as shown in Tables 3 and 4. In Table 3, regarding the causes of fine dust,

TABLE 2 Change of students' ideas on the pre- and post-IC-maps

Context level Pre-test Post-test

Personal Societal Global Total Personal Societal Global Total

(S)

(G)

(P)

(S)

(G)

\begin{tabular}{lrrrrrrrr}
\hline Cause (Cs) & 16 & 9 & 9 & 34 & 25 & 28 & 31 & 84 \\
Effect (Ef) & 10 & 6 & 7 & 23 & 34 & 19 & 22 & 75 \\
$\begin{array}{l}\text { Countermeasure } \\
(\mathrm{Cm})\end{array}$ & 19 & 7 & 9 & 35 & 45 & 31 & 19 & 95 \\
Total & 45 & 22 & 25 & 92 & 104 & 78 & 72 & 254 \\
\hline
\end{tabular}


TABLE 3 Changes of students' ideas on the causes and effects of fine dust by context levels

\begin{tabular}{|c|c|c|c|}
\hline & Personal & Societal & Global \\
\hline Causes & $\begin{array}{l}\text { Car exhaust }(+) \\
\text { Cooking }(+) \\
\text { Smoking }(+) \\
\text { Garbage } \\
\text { incineration }(+) \\
\text { Combustion }(+) \\
\text { Energy wasting }\left(^{*}\right) \\
\text { Low fine-dust } \\
\text { awareness }\left(^{*}\right) \\
\text { No ventilation }\left(^{*}\right)\end{array}$ & $\begin{array}{l}\text { Car exhaust }(+) \\
\text { Factory emission }(+) \\
\text { Garbage incineration } \\
\left({ }^{*}\right) \\
\text { Low fine-dust } \\
\text { awareness }\left(^{*}\right) \\
\text { Energy wasting }\left(^{*}\right) \\
\text { Urbanization }\left(^{*}\right) \\
\text { Scattering dust }\left(^{*}\right)\end{array}$ & $\begin{array}{l}\text { Factory emission }(+) \\
\text { Car exhaust }(+) \\
\text { Industrialization }(+) \\
\text { Energy wasting }\left(^{*}\right) \\
\text { Garbage incineration }\left(^{*}\right) \\
\text { Global warming }\left(^{*}\right) \\
\text { Low fine-dust awareness }\left({ }^{*}\right)\end{array}$ \\
\hline Effects & $\begin{array}{l}\text { Disease outbreak } \\
(+) \\
\text { Fine-dust increase } \\
(+) \\
\text { Car exhaust increase } \\
(+) \\
\text { Visibility reduction } \\
\left({ }^{*}\right)\end{array}$ & $\begin{array}{l}\text { Disease outbreak }(+) \\
\text { Air pollution }(+) \\
\text { Fine-dust increase }(+) \\
\text { Environment } \\
\text { pollution } \\
\text { Flight delay }\left(^{*}\right) \\
\text { Car accidents increase } \\
\text { Economic issues } \\
\text { occurred }\left({ }^{*}\right) \\
\text { Natural disaster }\left(^{*}\right)\end{array}$ & $\begin{array}{l}\text { Air pollution }(+) \\
\text { International conflict }(+) \\
\text { Multi-national damages }(+) \\
\text { Global warming }(+) \\
\text { Ecosystem destruction }(+) \\
\text { Fine-dust increase } \\
\text { Flight delay }\left(^{*}\right) \\
\text { Car accidents increase } \\
\text { Disease outbreak }\left(^{*}\right) \\
\text { Visibility reduction }\left(^{*}\right) \\
\text { Environment pollution }\left(^{*}\right)\end{array}$ \\
\hline
\end{tabular}

Note. + indicates that the number of ideas increased after the program.

* indicates that new ideas appeared after the program.

We listed concepts in descending order based on the number of student groups' answers.

the students listed "car exhaust," "factory emissions," and "cooking" in the preprogram IC maps. After the program, they included "garbage incineration," "energy wasting," "combustion," and "low fine-dust awareness." The personal level included "car exhaust," "cooking," and "smoking" both before and after the program. The students showed more concrete ideas on cooking such as "grilled mackerel," "grilled mackerel at home," and "grilled pork belly," indicating that they became aware that cooking greasy foods can be one of the cause of fine dust. They also listed "car exhaust" and "factory emissions" as causes at the societal and global levels. For example, they wrote "factory emissions from China," 
"fossil fuel gas burning in China" in the global context in both of the pre- and post-program IC maps. Ideas such as "smoking," "low fine-dust awareness," "no ventilation," and "scattering dust" appeared in the post-program IC maps.

There were some changes in students' ideas regarding the impacts and consequences of fine dust after the program. In the pre-program IC maps, the students wrote that fine dust caused illnesses at the personal and societal levels and air pollution at the societal and global levels. However, the ideas on the post-program IC maps showed that their understanding of the effects had expanded. They recognized that fine dust not only threatened individuals' health but caused transportation-related issues and socio-economic changes at the societal level. They also mentioned that because many countries in the world suffer from fine dust, international conflicts among the nations may intensify.

The number of ideas categorized as "disease outbreak" significantly increased at the personal level. The ideas on the pre-program IC maps included commonly mentioned responses such as "disease outbreak," "sore throat," and "lung cancer." However, on the post-program IC maps, the students wrote more specific symptoms or diseases such as "respiratory diseases," "conjunctivitis," "fetal disorder," "asthma," "brain damage," and "depression." This indicates that the program possibly contributed to expanding students' understanding of fine dust's impacts and consequences. Students listed some vocabulary that they learned when visiting community health centers and meeting experts or when conducting the activated carbon filtration experiment to understand the size and characteristics of fine dust. Such activities led students to experience the seriousness of the fine dust issue and to have raised awareness.

Table 4 shows the changes in ideas regarding the countermeasures to resolve the fine dust issue. On the pre-program IC maps, the students had mostly listed "public transportation use" and "eco-friendly practices" at the personal level. However, after the program, they suggested more expanded lists of efforts and policies to block or reduce fine dust at the personal, societal, and global levels, including "wearing masks," "energy saving," "ventilation," "washing hands," "dust collector installation," "international fine-dust policy," and "factory regulation."

Students' ideas written on the IC maps could be categorized into mitigation and adaptation. Mitigation implies efforts to reduce fine dust, whereas adaptation means actions to avoid being damaged. Mitigation included such responses as "public transportation use," "energy saving," and "eco-friendly practice." Adaptation contained the ideas such as "wearing masks," "washing hands," and "cleaning." At the personal level, they mostly listed "public 
TABLE 4 Changes of students' ideas on the Countermeasures of fine dust by context levels

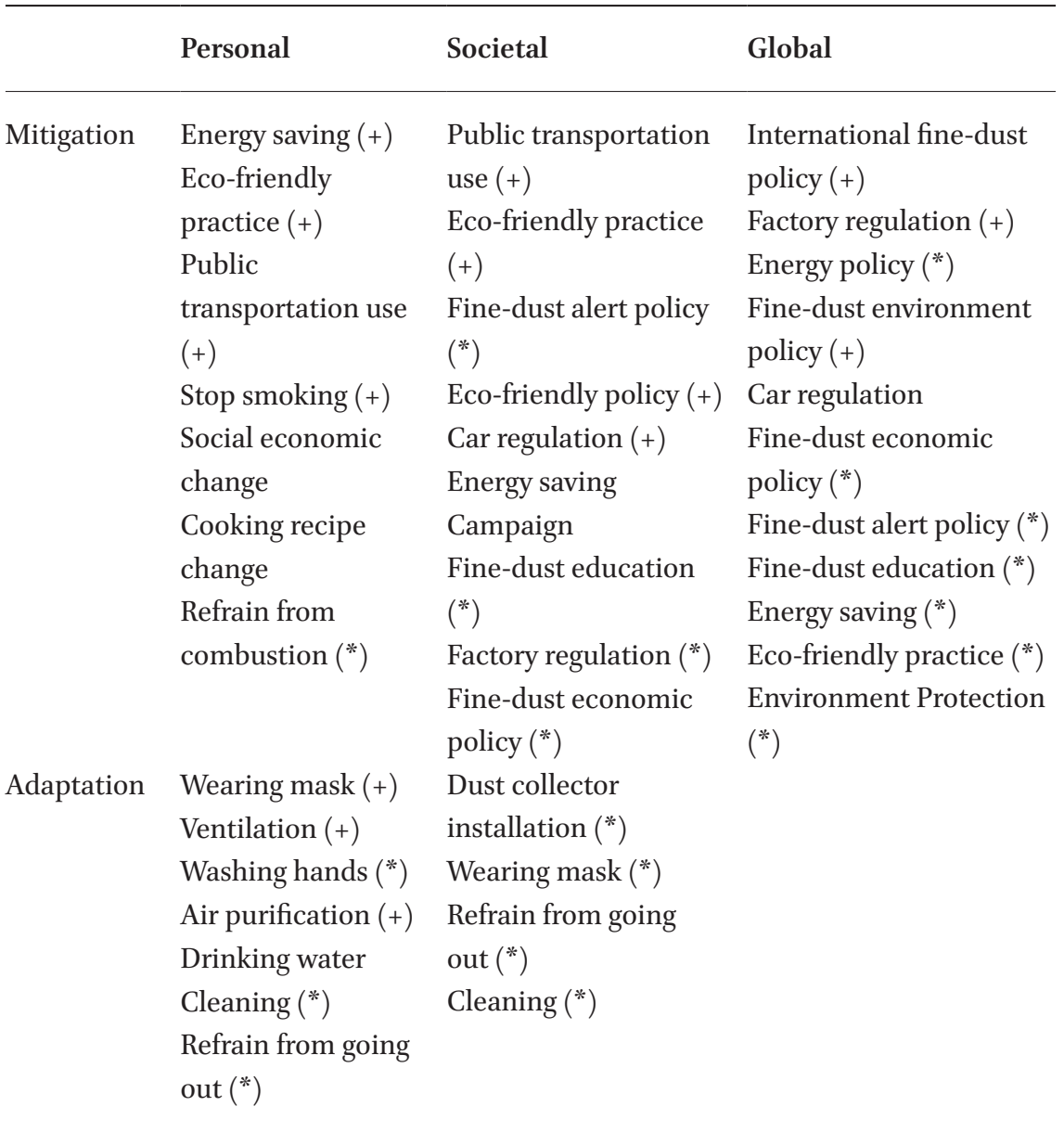

Note. + indicates that the number of ideas increased after the program.

* indicates that new ideas appeared after the program.

We listed concepts in descending order based on the number of student groups' answers.

transportation use" on the pre-program IC maps; however, after the program, they suggested more specific efforts to avoid the damage of fine dust (i.e., adaptation), such as "wearing masks," "refrain from going out" at the personal and societal levels. At a societal level, they had written "public transportation use" and "eco-friendly practice" on the pre-program IC maps. However, after the program, some of students came up with "dust collector installation," which could directly block the occurrence of fine dust, "public transportation use"; 
"eco-friendly practice"; and "energy saving." They also suggested "fine-dust alert policies," "factory regulation," "car regulation," "fine-dust education," and "fine-dust economic policy" to mitigate fine dust. On the pre-program IC maps, the students were unable to consider diverse countermeasures for fine dust at the global level. However, after the program, the students' ideas were varied and included "international fine-dust policy," "factory regulation," "fine-dust environmental policy," "energy policy," "fine-dust economic policy," "fine-dust alert policy," and "fine-dust education." However, they were not able to write any ideas regarding adaptation at the global level. We assumed that the ssi program contributed to helping students have more specific ideas about countermeasures by providing opportunities to have firsthand experience of choosing the right face masks and wearing them appropriately.

Although the students presented more expanded views about fine dust after the program, they still had misunderstandings about fine dust issues, as shown in Table 5. This resonates with the previous studies. Some researchers (An et al., 2020; Kim \& Lee, 2017; Kim et al., 2016) have reported that students and the general public often confused fine dust with yellow sand in terms of their causes and chemical compositions. Yellow sand refers to the sand dust drifting from deserts in China carried by westerly winds, while fine dust can be categorized into PM1O (fine dust) and PM 2.5 (ultrafine dust). Yellow sand includes fine dust and ultrafine dust, but is sometimes larger. Yellow sand affects the increase of fine dust rather than ultrafine dust concentrations while moving long distances carried by westerly winds (Gong et al., 2012). People

TABLE 5 Students groups' answers related to yellow sand

Students groups' Cause Countermeasure

answer

Personal Societal Global Personal Societal Global

(P)

(S)

(G)

(P)

(S)

(G)

\begin{tabular}{lllllll}
\hline Yellow sand & - & - & 3 & - & - & - \\
Yellow sand from & - & - & 9 & - & - & - \\
China & & & & & & \\
Desertification & - & - & 3 & - & - & - \\
Desert in China & - & 1 & 2 & - & - & - \\
Planting in desert & - & - & - & - & - & 3 \\
Total & - & 1 & 17 & - & - & 3 \\
\hline
\end{tabular}


tend to think that fine dust issues are caused by China partly because mass media often use expressions such as "fine dust from China" (Kim et al., 2016). The students in this study also had difficulty in distinguishing fine dust from yellow sand. They listed "yellow sand," "yellow sand from China," "desertification," and "deserts in China" as the causes of fine dust. Because of this, some students suggested "planting trees in China" as a countermeasure to the fine dust issues, and while planting trees contributes to preventing desertification in China, it is not a direct solution to the problem of fine dust.

\subsection{Changes in Connections among Ideas}

The students made connections between the ideas using arrows and straight lines as they drew their IC maps. Arrows represented causal relationships whereas straight lines indicated simple connections among the ideas. Compared to the pre-program IC maps, they made more connections among the ideas on the post-program IC maps. Depending on how they made connections on the pre- and post-program IC maps, we classified them into six cases, as shown in Table 6. Out of 14 groups of students, Group 10 (Case 1) could not make any connections both on the pre- and the post-program IC maps. Students in Groups 3, 5, 7, and 14 (Case 4) presented only one type of connection on the pre- and post-program IC maps. However, nine groups of students (Cases 2, 3, 5, and 6) presented more various types of connections among the ideas on the post-program IC maps.

More specifically, on the pre-program IC maps, students in Cases 1, 2, and 3 could not make any connections among the ideas. Students in Cases 4, 5, and 6 made one type of connection among the causes (C), effects (E), and countermeasures $(\mathrm{Cm})$ within a certain context (e.g., grilled pork belly $(\mathrm{C}) \rightarrow$ smog occurring (E) $\rightarrow$ eating boiled pork belly $(\mathrm{Cm})$, at the personal level). However, on the post-program IC maps, students in Cases 2, 3, 5, and 6 created more types of connections (i.e., P-S-G in the same or different occurrence(s), connections within a cell). An example of P-S-G in the same occurrence is "respiratory disease outbreak (E) at the personal level $\rightarrow$ patient increases in hospitals (E) at the societal level." P-S-G in the different occurrences can be shown in the example of "causes a lot of environmental pollution (C) at the societal level $\rightarrow$ air pollution (E) at the global level". Such lines of connection provided some clues as to what extent students carefully examined the ideas from different angles and tried to determine the relationships. Not being able to make any connections among the ideas means that they might experience difficulties in understanding causal relationships or expanding their ideas to larger contexts. 
TABLE 6 Change of connections between ideas

\begin{tabular}{|c|c|c|c|}
\hline Case & Pre-IC map & Post-IC map & Group \\
\hline 1 & None & None & G10 \\
\hline 2 & None & C-E-Cm in the same context & $\mathrm{G}_{11}, \mathrm{G}_{12}, \mathrm{G}_{13}$ \\
\hline 3 & None & $\begin{array}{l}\text { C-E-Cm in the same context } \\
\text { P-S-G in the same occurrence } \\
\text { P-S-G in the different occurrences }\end{array}$ & $\mathrm{G}_{3}, \mathrm{G}_{5}, \mathrm{G}_{7}, \mathrm{G}_{14}$ \\
\hline 4 & $\begin{array}{l}\mathrm{C}-\mathrm{E}-\mathrm{Cm} \text { in the same } \\
\text { context }\end{array}$ & $\mathrm{C}-\mathrm{E}-\mathrm{Cm}$ in the same context & $\mathrm{G}_{1}, \mathrm{G}_{4}, \mathrm{G} 6$ \\
\hline 5 & $\begin{array}{l}\mathrm{C}-\mathrm{E}-\mathrm{Cm} \text { in the same } \\
\text { context }\end{array}$ & $\begin{array}{l}\text { C-E-Cm in the same context } \\
\text { P-S-G in the same occurrence }\end{array}$ & G2 \\
\hline 6 & $\begin{array}{l}\text { C-E-Cm in the same } \\
\text { context }\end{array}$ & $\begin{array}{l}\text { C-E-Cm in the same context } \\
\text { P-S-G in the same occurrence } \\
\text { P-S-G in the different occurrences } \\
\text { Connections within a cell }\end{array}$ & G8 \\
\hline
\end{tabular}

Note. C: Cause, E: Effect, Cm: Countermeasure, P: Personal level, S: Societal level, G: Global level

As shown in Table 6, most student groups were able to draw connections of cause-effect-countermeasure in the same context level. However, personalsocietal-global level connections were relatively rare. These results resonate with the previous study on climate change issues (Mun et al., 2014), In this study, we present two cases, Cases 5 and 6, to show the ways that students made connections on both the pre- and post-program IC maps and the patterns of changes in their connections.

\subsubsection{Connections in Case 5}

On the pre-program IC maps, as shown in Figure 2, Group 2 only drew causeeffect-countermeasure connections at the personal level. Group 2 revealed that indoor cooking such as grilled mackerel and pork belly causes fine dust to be produced and suggested alternative recipes that do not burn oil. They also wrote "factory smog" without any connection to possible impacts and countermeasures. However, after the program, the students not only wrote more ideas in the nine cells but also connected the ideas mostly at the same level of context. In other words, they extended the connections from causes to effects and countermeasures at the societal or global level. For example, they wrote, "much factory smog from China" at the global level (GC) and drew an arrow 


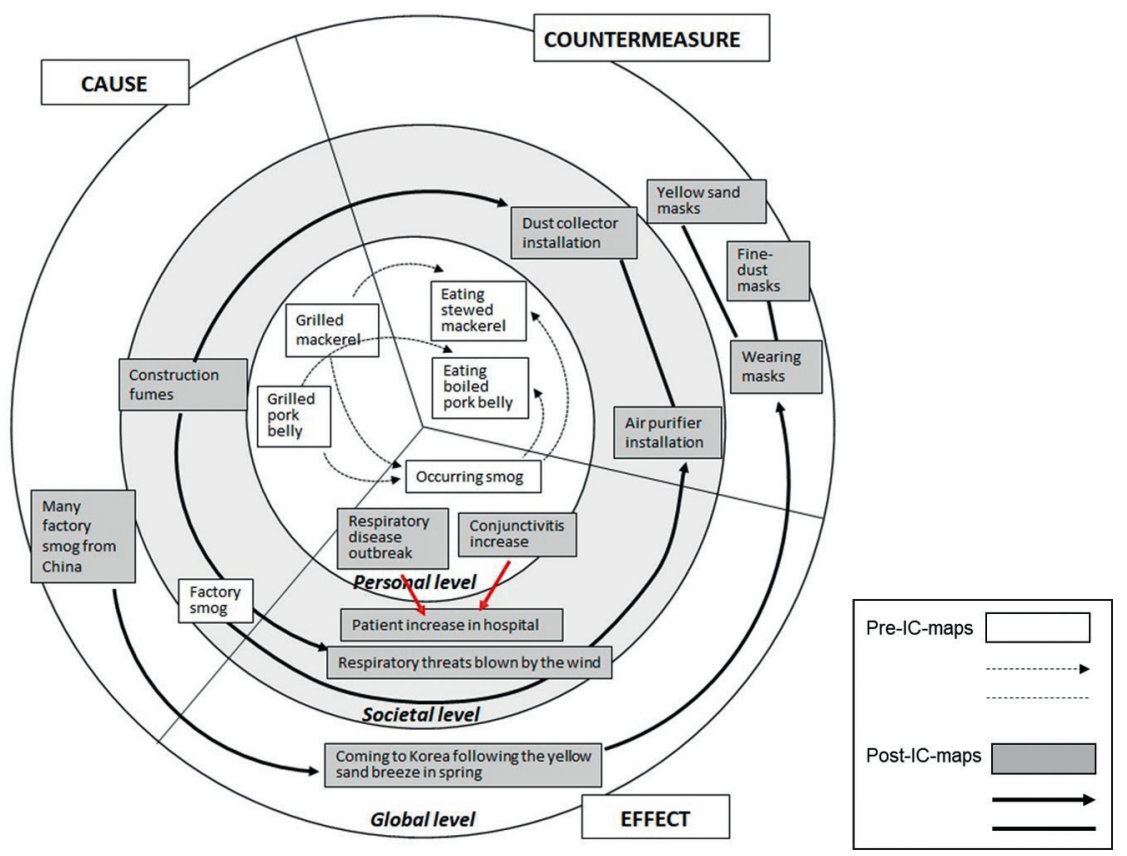

FIGURE 2 Changes of group 2's IC map

to "coming to Korea following the yellow sand breeze in spring" at the global level (GE), and went further to "wearing masks" in the global context (GCm). As another example, they drew a connection from "construction fumes" at the societal level (SC) to "respiratory threats blown by the wind" (SE) and "dust collector installation" at the societal level (SCm). In addition, Group 2 drew connections from personal to societal levels within the effect cells. They used arrows from "respiratory disease outbreak" (PE) and "conjunctivitis increase" $(\mathrm{PE})$ at the personal level to "patient increase in hospital" in the societal context $(\mathrm{SE})$. This indicates that the students became aware that the fine dust issue was not limited to the personal level of issues and could threaten our society and the entire world.

\subsubsection{Connections in Case 6}

Before the ssi program, as shown in Figure 3, Group 6 only drew cause-effectcountermeasure connections at the global level. They understood that yellow sand drifting on the wind from China could damage China, Japan, and Korea, and so suggested installing air filtering equipment in Chinese factories as a countermeasure to mitigate ultrafine dust. They also wrote "get a disease" 


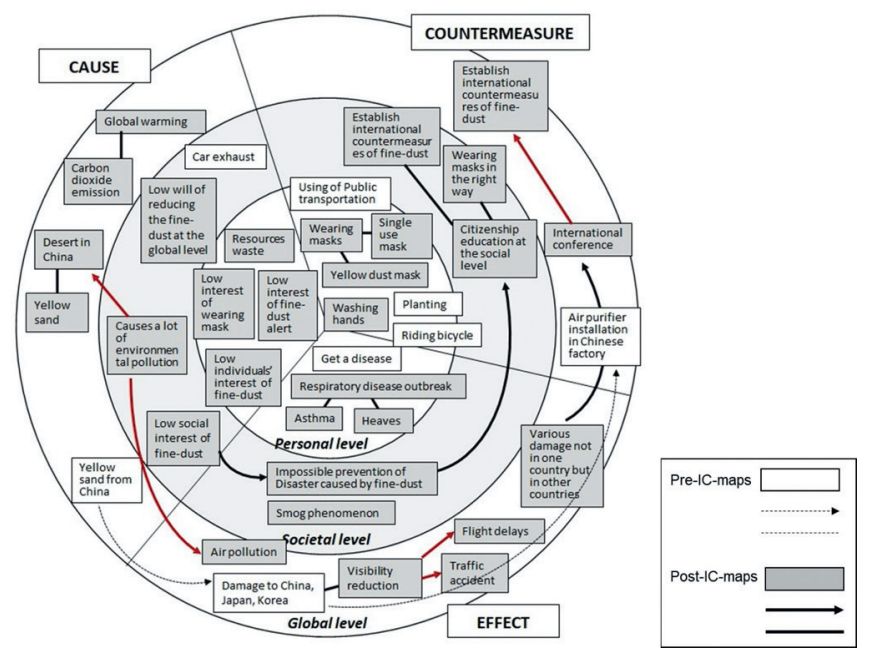

FIGURE 3 Changes of group 6's IC map

$(\mathrm{PE})$, "riding a bicycle" (PCm), "planting" (PCm), "using public transportation" (PCm), and "car exhaust" (sc) without any connections with other ideas. However, after the ssi program, the nine cells of their IC map were filled with many ideas. The students also presented different types of connections among the ideas: cause-effect-countermeasure connections in the same context, personal-societal-global level connections in the same occurrence, personalsocietal-global level connections in different occurrences, and connections within a cell.

Regarding the cause-effect-countermeasure connection in the same context, for instance, students wrote, "low social interest in fine dust" as a societal cause (sc) and considered what kinds of impact we could expect at the societal level because of this cause. Thus, they wrote, "impossible prevention of disaster caused by fine dust" as a societal effect (SE) and came up with a possible countermeasure, which was "citizenship education" at the societal level (SCm). They also suggested other countermeasures such as "establish international countermeasures of fine dust" and "wearing masks in the right way" at the societal level $(\mathrm{SCm})$. As an example of personal-societal-global level connections in the same occurrence, they drew the connection from "causes a lot of environmental pollution" at the societal level (sc) to "desert in China" at the global level (GC) as a cause of fine dust. They understood that "environmental pollution" was the cause of fine dust at the societal level (sc) and was affected by the "desert in China" at the global level (GC). An example of the personalsocietal-global level connection in different occurrences is "environmental 
pollution" at the societal level (sc) in the connection with "air pollution" at the global level (GE). Last, connections within a cell indicated that they expanded their ideas of fine dust within the same cell. For instance, students wrote, "visibility reduction" as a global effect (GE) and added more ideas such as "flight delays" (GE) and "traffic accidents" (GE) as global effects.

\section{$4 \quad$ Conclusion and Implications}

In the current study, we aimed to introduce IC maps as an effective instructional tool for exploring students' ideas about issues. By visualizing students' ideas in two dimensions, context and occurrence, we were able to observe what kinds of ideas they had, how their ideas changed after the program, and in what ways they made connections among the ideas. Based on the results, we would like to suggest some educational implications.

First, the ssi program resulted in students' ideas of fine dust issues having turned into more concrete and practical concepts. Before participating in the ssi program, they mostly presented common causes and solutions using broad terms such as factory, disease, planting, and environmental pollution. However, after the ssi program, students became aware that gas emitted from industrial factories is a source of fine dust and that fine dust specifically can cause "respiratory diseases" and not just "diseases" in general. They also proposed more practical countermeasures to prevent diseases such as wearing masks and washing hands. It seems that their continuous engagement in various activities through the ssi program provided the students with greater interest and awareness of community issues (Birmingham \& Barton, 2014) and provided more opportunities to apply their ideas and knowledge learned at school to daily life (Morgan, 2011; Smith, 2002; Theobald \& Curtiss, 2000).

Second, IC maps showed that students' understanding of the causes of, effects of, and countermeasures to deal with fine dust issues increased, and at the same time, they considered the issues not only in the personal context but also in the societal and global contexts. Since fine dust issues were no longer viewed as an individual and country-specific problem, such changes can be regarded as very significant educational effects. However, some students still showed a misunderstanding of fine dust. While thinking about the cause of fine dust as "yellow sand from China," they suggested asthma and pulmonary emphysema as consequences on personal health caused by fine dust. However, asthma are pulmonary emphysema are diseases that can be caused by ultrafine dust and are affected by harmful substances contained in ultrafine dust. That is, natural dust is different from the fine dust, which is artificially generated 
by the combustion of fossil fuels, and its components. As another example, "planting trees in Chinese deserts," suggested by students as a countermeasure against fine dust may be a measure to reduce yellow dust, but is limited in ultimately solving the fine dust problem.

The above results show that IC maps can be an effective instructional tool to examine students' ideas about ssis. ssis, such as fine dust issues, are caused by various factors and have influences on various sectors of society. Diverse stakeholders need to gather to collaborate come up with solutions to ssis because of the intrinsic complexity of the issues. IC maps can scaffold students to consider occurrences (causes, effects, and countermeasures) and contexts (personal, societal, and global) as they fill in the nine cells of IC maps. In addition, by using lines or arrows to display the relationships between concepts, students are able to understand better the causes of, effects of, and countermeasures to deal with ssis. In addition, by visualizing the process of learning and discussion on IC maps, they can reflectively observe their learning in groups. Teachers can also evaluate students' understanding and misconceptions as they review students' responses on IC maps.

\section{Abbreviations}

IC maps Issue Concept maps

ssis Socioscientific Issues

\section{Ethical Considerations}

The data collected from this paper has obtained the necessary clearance from guardians and the students involved in the study.

\section{Ahout the Authors}

Gahyoung Kim is postdoctoral fellow in research center for hazard literacy education at Ewha Womans University in Seoul, Republic of Korea. Her research focuses on designing and implementing community-based education formal and informal settings on ssi. Especially, she is interested in engaging students in learning and applying the learned knowledge to everyday life as activists in their community. 
Kongju Mun is educational research scientist interested in investigating the affective factors of learning science, in particular students' emotions and aesthetic experiences in interdisciplinary curriculum such as STEAM. She is also interested in motivation toward learning science and investigated self-efficacy, task-commitment, and grit. Her recent research reveales importance of grit in the long-term scientific project.

Hyunju Lee is a professor at Ewha Womans University, Seoul, South Korea. Her research centers on science teaching and teacher professional development for socioscientific issues (ssis). She has published papers that address patterns of decision-making on ssis, instructional approaches to ssis, and the development of teachers' practical knowledge on ssi teaching.

\section{References}

An, S., Lee, S., \& So, K. (2020). The effects of environmental education program on fine dust on elementary school students' knowledge: Perception and attitude of the fine dust. Korean Journal of Environmental Education, 33(1), 76-89.

Anderson, B., \& Wallin, A. (2000). Students' understanding of the greenhouse effect, societal consequences of reducing $\mathrm{CO}_{2}$ emissions and why ozone layer depletion is a problem. Journal of Research in Science Teaching, 37(10), 1096-1111.

Birmingham, D., \& Barton A. C. (2014). Putting on a green carnival: Youth taking educated action on socioscientific issues. Journal of Research in Science Teaching, 57(3), $286-314$.

Boon, H. J. (2010). Climate change? Who knows? A comparison of secondary students and pre- service teachers. Australian Journal of Teacher Education, 35(1), 104-120.

Boyes, E., \& Stanisstreet, M. (1997). The environmental impact of cars: Children's ideas and reasoning. Environmental Education Research, 3(3), 269-282.

Brody, M., Chipman, E., \& Marion, S. (1989). Student knowledge of scientific and natural resource concepts concerning acidic deposition. Journal of Environmental Education, 20(2), 32-42.

Chithra, V. S., \& Madanayak, S. N. (2018). Source identification of indoor particulate matter and health risk assessment in school children. Journal of Hazardous, Toxic, and Radioactive Waste, 22(2), 162-176.

Choi, S. (2018). A study on the factors affecting fine dust cognition, knowledge, and attitude among college students. The Journal of the Korea Contents Association, 18(12), 281-29o. 
Deng, Q., Lu, C., Li, Y., Sundell, K., \& Norback, D. (2016). Exposure to outdoor air pollution during trimesters of pregnancy and childhood asthma, allergic rhinitis, and eczema. Environmental Research, 150, 119-127.

Dijkstra, E. M., \& Goedhart, M. J. (2012). Development and validation of the ACSI: Measuring students' science attitudes, pro-environmental behaviour, climate change attitudes and knowledge. Environmental Education Research, 18(6), 733-749.

Gong, S. Y., Bae, H. J., Yoon, D. O., Hong, S. P., \& Park, H. Y. (2012). A study on the health impact and management policy of PM2.5 in Korea. Sejong: Korea Environment Institute.

Herman, B. C. (2018). Students' environmental NOS views, compassion, intent, and action: Impact of place-based socioscientific issues instruction. Journal of Research in Science Teaching, 55(4), 6oo-638.

Jorgensen, B. S., \& Stedman, R. C. (2001). Sense of place as an attitude: Lakeshore owners attitudes toward their properties. Journal of Environmental Psychology, 21, 233-248.

Kahn, S., \& Zeidler, D. L. (2016). Using our heads and HARTSS*: Developing perspectivetaking skills for socioscientific reasoning ( ${ }^{*}$ Humanities, ARTs, and Social Sciences). Journal of Science Teacher Education, 27(3), 261-281.

Kim, G., \& Lee, H. (2017). Effects of community-based SSI programs on promoting middle school students' understanding of issues and character and values as citizens: Focused on fine dust issues. Journal of the Korean Association for Science Education, 37(6), 911-920.

Kim, G., \& Lee, H. (2019). A case study of community-based socioscientific issue program: Focusing on the abandoned animal issue. Journal of Biological Education, 1-15. doi:10.108o/oo219266.2019.169915o.

Kim, G., Ko, Y., \& Lee, H. (2020). The effects of community-based socioscientific issues program (SSI-COMM) on promoting students' sense of place and character as citizens. International Journal of Science and Mathematics Education, 18(3), 399-418.

Kim, J. M. (2018). A survey on the cognition of particulate matter and the necessity of education for high school students for appropriate response. Unpublished master's thesis, Graduate School of Environmental Life Korea University, Seoul, Korea.

Kim, Y. W., Lee, H. S., Jang, Y. J., \& Lee, H. J. (2015). How does media construct particulate matter risks? : A news frame and source analysis on particulate matter risks. Korean Journal of Journalism \& Communication, 59(2), 121-154.

Kim, Y. W., Lee, H. S., Lee, H. J., \& Jang, Y. J. (2016). A study on differences between experts and lay people about risk perceptions toward particulate matter: A focus on the utilization of mental models. Communication Theories, 12(1), 53-117.

Lee, S. (2018). Korea's new comprehensive plan on fine dust and its implications for policy and research. Research in Brief, 29, 1-7. 
Lincoln, Y., \& Guba, E. (1985). Naturalistic inquiry. Thousand Oaks, CA: Sage.

Morgan, A. (2011). Place-based education versus geography education. Geography, Education and the Future, 94, 84-108.

Mun, K., Kim, J., Kim, S. W., \& Krajcik, J. (2014). Exploration of high school students' concepts about climate change through the use of an issue concept map (IC-Map). In International Conference on Science Education 2012 Proceedings (pp. 209-222). Berlin, Heidelberg: Springer.

Newton, M. H., \& Zeidler, D. L. (2020). Developing socioscientific perspective taking. International Journal of Science Education, 42(1), 1-18.

Novak, J. D. (199o). Concept mapping: A useful tool for science education. Journal of Research in Science Teaching, 27(10), 937-949.

Novak, J. D., \& Gowin, D. B. (1984). Learning how to learn. Cambridge University press.

Park, S. H. (2014). A study on the evaluation of the awareness and the development of environmental education program about the particulate matter in the ambient air: Focused on middle school students. Unpublished master's thesis, Graduate School of Education Yonsei University, Seoul, Korea.

Powers, A. L. (2004). An evaluation of four place-based education programs. Reports \& Research, 35(4), 17-32.

Semken, S., \& Freeman, B. C. (2008). Sense of place in the practice and assessment of place-based science teaching. Science Education, 92, 1042-1057.

Semken, S., Freeman, B. C., \& Watts, N. B. (2009). Factors that influence sense of place as a learning outcome and assessment measure of place-based geoscience teaching. Electronic Journal of Science Education, 13(2), 136-158.

Smith, G. A. (2002). Place-based education: Learning to be where we are. Phi Delta Kappan, 83(8), 584-594.

Tekbiyik, A. (2015). The use of jigsaw collaborative learning method in teaching socioscientific issues: The case of nuclear energy. Journal of Baltic Science Education, 14(2), 237-253.

Theobald, P., \& Curtiss, J. (2000). Communities as curricula. Forum for Applied Research and Public Policy, 15(1), 106-111. 